\title{
Materiais nanoestruturados em intervenções de reabilitação de Património Arquitetónico
}

\author{
Carlos Manuel Franco
}

Resumo: Este artigo tem como objetivo contribuir e estimular a introdução de materiais nanoestruturados nas intervenções de reabilitação, possibilitando a execução de novos rebocos com propriedades fotocatalíticas conferidas pela adição de nanopartículas de $\mathrm{TiO}_{2}$ na matriz da argamassa, entre as quais se destacam as de autolimpeza e de descontaminação ambiental. A adição de nanotubos de carbono nas argamassas e na constituição de betão, permite o fabrico de revestimentos de desempenho mecânico melhorado, assim como de peças estruturais de menores dimensões, proporcionando uma intervenção que se deseja mínima e pouco intrusiva, garantindo uma maior rapidez de execução.

Procurar soluções para as patologias do Património, visando a mitigação dos efeitos nefastos para o ambiente provocados pela exposição aos gases poluentes - NOx, $\mathrm{CO}_{2}$ e aos compostos orgânicos voláteis - COVs, resultando, consequentemente, na aceleração da degradação das fachadas dos edifícios, num modelo mais sustentável, será o grande desafio dos arquitetos e demais especialistas envolvidos.

Palavras-chave: nanomateriais, rebocos, sustentabilidade, fotocatálise, reabilitação, Património Arquitetónico

\section{Nanostructured materials in interventions for rehabilitation of Architectural Heritage}

Abstract: This article aims to contribute and stimulate the introduction of nanostructured materials in the rehabilitation interventions, enabling the execution of new plasters with photocatalytic properties conferred by the addition of $\mathrm{TiO}_{2}$ nanoparticles in the mortar matrix, among which are self - cleaning and decontamination environmental. The addition of carbon nanotubes in mortars and the formation of concrete allows the fabrication of coatings of improved mechanical performance as well as smaller structural parts, providing a minimal and intrusive intervention, ensuring a faster execution time.

To seek solutions to pathologies in architectural heritage, aiming to mitigate the harmful effects to the environment caused by the exposure to the polluting gases - $\mathrm{NOx}, \mathrm{CO}_{2}$ and to the volatile organic compounds - VOCs, resulting, consequently, in accelerating degradation of facades of buildings, in a model more sustainable, will be the great challenge of architects and other specialists involved.

Keyword: nanomaterials, mortars, sustainability, photocatalysis, rehabilitation, Architectural Heritage

\section{Materiais nanoestruturados em intervenções de reabilitação de Património Arquitetónico}

Resumen: Este artigo tem como objetivo contribuir e estimular a introdução de materiais nanoestruturados nas intervenções de reabilitação, possibilitando a execução de novos rebocos com propriedades fotocatalíticas conferidas pela adição de nanopartículas de $\mathrm{TiO}_{2}$ na matriz da argamassa, entre as quais se destacam as de autolimpeza e de descontaminação ambiental. A adição de nanotubos de carbono nas argamassas e na constituição de betão, permite o fabrico de revestimentos de desempenho mecânico melhorado, assim como de peças estruturais de menores dimensões, proporcionando uma intervenção que se deseja mínima e pouco intrusiva, garantindo uma maior rapidez de execução.

Procurar soluções para as patologias do Património, visando a mitigação dos efeitos nefastos para o ambiente provocados pela exposição aos gases poluentes - $\mathrm{NOx}, \mathrm{CO}_{2}$ e aos compostos orgânicos voláteis - COVs, resultando, consequentemente, na aceleração da degradação das fachadas dos edifícios, num modelo mais sustentável, será o grande desafio dos arquitetos e demais especialistas envolvidos.

Palabras-clave: nanomateriais, rebocos, sustentabilidade, fotocatálise, reabilitação, Património Arquitetónico 


\section{Introdução}

O presente estudo visa sobretudo apresentar uma revisão bibliográfica sobre a aplicação da nanotecnologia com referência a Nanomateriais disponíveis para a construção, nomeadamente para uso em intervenções de reabilitação, proporcionando ao arquiteto - entre outros especialistas, a oportunidade para a definição de novas metodologias de atuação pouco intrusivas, garantindo a autenticidade do património arquitetónico, com recurso a novos materiais com novas características e novas propriedades. Revestimentos fotocatalíticos com características de autolimpeza e de descontaminação ambiental, de maior durabilidade, proporcionam uma intervenção mais sustentável.

O esgotamento dos recursos naturais exige a extração de matéria-prima a distâncias cada vez maiores. Desde a primeira revolução industrial - há cerca de 250 anos, que se assiste a um amento contínuo da emissão antropogénica de $\mathrm{CO}_{2}$, resultando num acréscimo de $40 \%$ deste gás comparativamente aos valores existentes na era pré-industrial, resultantes principalmente da queima de combustíveis fósseis e a utilização desenfreada de fertilizantes e pesticidas na indústria agroalimentar, com a consequente inquinação por efeito do processo de eutrofização dos sistemas aquáticos.

O aumento da acidez das águas da chuva - $\mathrm{pH}<5$, constitui um dos maiores problemas ambientais da atualidade. Este fenómeno acontece principalmente devido ao aumento na concentração de óxidos de enxofre $-\mathrm{SO}_{2}$ e $\mathrm{SO}_{3^{\prime}}$ e óxidos de azoto como o $\mathrm{NO}_{2}$ e $\mathrm{NO}_{3}-\mathrm{NOx}$, que constituem um grupo designado por óxidos ácidos.

Precipitações contendo substâncias com $\mathrm{pH}<5$, provocam danos sobre património histórico, principalmente quando revestidos a calcário ou em elementos de bronze. Pode-se observar o escurecimento das fachadas de mármore do Taj Mahal - India, declarado património mundial pela Unesco, provocado pela deposição seca de gases tóxicos (Santos et al 2018: 53-59).

Persistir num modelo económico linear de "extrair -consumir -descartar" não será viável, pelo que impõe -se mudar a abordagem estratégica (Fundo Ambiental Aviso n. ${ }^{\circ} 6907 / 201$, DR no 119/2017).

A Transição para uma Economia Circular tem como principais objetivos a redução de extração de matériaprima, de consumo de água, produção de resíduos e emissões GEE - gases efeito estufa, e demais poluentes atmosféricos. A economia circular, enquanto um modelo económico, visa a distribuição equilibrada dos recursos. Modelo assente no desenvolvimento de estratégias com recurso a novas metodologias e novos materiais - capaz de reduzir a dependência da extração de matérias-primas, preconiza a reutilização contínua de materiais e recursos, em ciclos devidamente energizados por fontes renováveis.
A Melhoria da eficiência dos recursos utilizados, num contexto de disponibilidade real e limitada de recursos, deverá assim assegurar a rentabilidade económica e redução de impactos ambientais, associada à preservação dos recursos através de estratégias de circularidade; com introdução de soluções inovadoras apoiadas em novas tecnologias. Será, contudo, necessário fomentar o investimento em soluções circulares, preconizando o aumento eficiência energética e hídrica e a durabilidade dos materiais, assim como promover uma maior utilização de energias renováveis de forma a desenvolver soluções tecnológicas e não tecnológicas, que possam ser adotadas, divulgadas e replicadas, aumentando a produtividade dos recursos utilizados pelos agentes económicos envolvidos, incluindo o utilizador final (disponível em https://www. fundoambiental.pt/avisos/programa-apoiar-a-transicaopara-uma-economia-circular-fase-i.aspx).

A indústria da construção terá de implementar a incorporação de resíduos produzidos pela própria indústria da construção civil e demolição (RC\&D) em particular, visando a produção de materiais recicláveis, com baixa energia incorporada. $\mathrm{O}$ fabrico de betões com características pozolânicas, com a introdução de escórias de alto-forno, sílica de fumo, cinzas de resíduos vegetais, cinzas volantes e/ou de resíduos sólidos urbanos resultantes das mais variadas atividades industriais, em conjugação com uma seleção de materiais a utilizar, com uma análise cuidada do ciclo de vida (ACV), garantirão uma maior economia e sustentabilidade do setor (Torgal 2010: 20-24).

A natureza tornou-se a grande fonte de inspiração para os investigadores, perante a fascinante variedade de soluções de designapresentado pormateriais biológicos, satisfazendo os requisitos estruturais e funcionais necessários á sua especificidade. A verificação de que a nano e microestrutura existente nos sistemas biológicos difere da estrutura dos materiais sintéticos, que apresenta alternativas de design para a fabricação de materiais funcionais, de estrutura biológica e ambientalmente sustentável, vem possibilitar a replicação dos princípios de design subjacentes à resposta funcional das estruturas naturais.

A compreensão das condições e da técnica de aplicação das estruturas naturais - e não apenas se limitar à cópia da composição química e da estrutura dos materiais biológicos, estará sem dúvidas na génese da concepção de materiais da próxima geração.

Projetos de estrutura do nano, ao micro e às escalas macroscópicas, aproveitando os princípios de design que foram conseguidos ao longo de centenas de milhões de anos de evolução na natureza, vêm possibilitar a fabricação de estruturas com novas e melhoradas funcionalidades, para uma ampla gama de aplicações, oferecendo-nos uma plataforma tecnológica poderosa para a fabricação de materiais funcionais e elementos estruturais mais duráveis e sustentáveis (Hebel y Heisel 2017: 158-166). 
A revisão bibliográfica sobre materiais nanoestruturados com aplicação na indústria da construção - publicada entre 2005 e 2018 tem como objetivo reunir de uma forma sucinta informações gerais e definições de nanotecnologia, com enfoque nas nanopartículas quando usadas como nano-aditivos mais eficazes, capazes de melhorar substancialmente as propriedades dos revestimentos aditivados com nano dióxido titânio $\mathrm{TiO}_{2}$, ou com nanotubos de carbono - NTC no reforço estrutural.

A metodologia adotada nesta pesquisa, sendo um tema em constante evolução em que se assiste a nível global a um aumento exponencial de novos materiais nanoestruturados com novas potencialidades, teve como plataforma de trabalho a consulta de bibliografia específica e pesquisas de artigos científicos recentemente publicados sobre nanotecnologia e Nanomateriais.

Foram ainda consultadas livrarias científicas disponíveis em linha, nomeadamente a Web of Science, Scientific Electronic Library, no endereço http://www.scielo.br, e a artigos científicos apresentados no Congresso Luso-Brasileiro de Materiais de Construção Sustentáveis, disponível em http://repositorium.sdum.uminho.pt/.

\section{Contextualização}

Desde o ano 5.000 a.C. que na Mesopotâmia se juntava palha aos tijolos usados na construção, aumentado a sua capacidade de resistência, reduzindo a fissuração durante o processo de secagem. Este ancestral compósito em que a lama funcionava como matriz polimérica e a palha como fibras de reforço, tirando vantagens das características de cada um individualmente, potencializando o seu desempenho quando em conjunto, vem demonstrar que o conceito de materiais compósitos já existia na antiguidade. (Lima2014:20; Gonçalves y Margarido 2012: 576).

Sem que nas antigas civilizações existisse entendimento teórico do desenvolvimento do fenómeno, o domínio da técnica evoluía com os resultados da experiência, baseada puramente na tentativa e erro, em processos tecnológicos que integravam e/ou formavam nanopartículas no compósito resultante. Um exemplar extraordinário fabricado pelos romanos, datado do século IV d.C., é o Cálice de Licurgo, que contém nanopartículas de ouro e prata [figura 1].

No entanto somente em finais do seculo XX - mais especificamente no ano de 1990, é que foi possível aos cientistas obter a resposta para o dicroísmo observado, em resultado da análise efetuada com recurso a um microscópio atómico de varrimento, que ocorre devido à presença de nanopartículas na composição da matriz de vidro: $66,2 \%$ de prata; $31,2 \%$ de ouro e $2,6 \%$ de cobre. A cor vermelha resulta da absorção de luz pelas nanopartículas de ouro ( 520nm). A cor púrpura é observada quando a
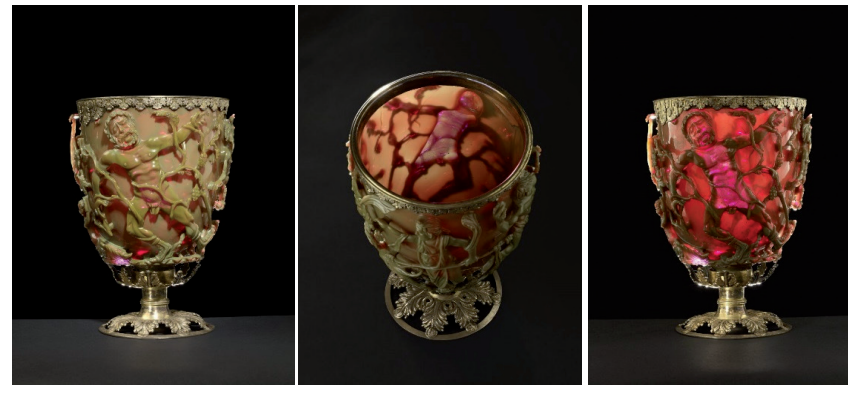

Figura 1.- Cálice de Licurgo. Fonte: The British Museum 2019.

luz é absorvida devido a partículas maiores, sendo que a cor verde é conseguida através do espelhamento de luz por dispersões coloidais de partículas de prata, com dimensões maiores a 40nm.

A adição destas pequenas partículas na fusão prolongada do vidro terá dado origem á formação das nanopartículas metálicas, conferindo-lhe a particularidade de mudança de cor apenas com a mudança de posição da origem da luz: apresenta uma cor verde-ervilha á luz ambiente (reflexão da luz exterior), transmitindo a cor magenta quando a fonte de luz é localizada no seu interior. Na idade Media os artífices - alquimistas, sobretudo nas igrejas cristãs, já utilizavam nanopartículas de ouro e prata - com dimensões entre 40 a 100nm, na fusão com o vidro colorido dos vitrais, proporcionando o reflexo de luz vibrante (Lima 2014: 79; Loos 2014: 16-22).

Pode-se assim concluir que o conceito de Nanotecnologia - apesar de ser atual, parte da tecnologia incorporada nesta nova ciência era desde há muitos séculos utilizada na prática, mesmo que na época os artificies não dominassem a sua fundamentação teórica.

O termo nanotecnologia foi apenas apresentado muitos séculos depois por Norio Taniguchi - professor da universidade de Tóquio, no ano de 1974 (Lima 2014: 79).

Richard P. Feynman, no ano de 1959, apresenta a sua celebre palestra sob o tema "There's plenty of room at the bottom", no encontro anual promovido pela Sociedade Americana de Física, no Instituto de Tecnologia da Califórnia-CalTech, afirmando que seria possível condensar na cabeça de um alfinete os 24 volumes completos da Enciclopédia Britânica, estabelecendo a data do início da era da nanotecnologia. (Cristina 2014: 5-16; Roz et al 2015a).

A escala de comprimento no topo varia de $1 \mathrm{~m} \mathrm{a} 10^{-10} \mathrm{~m}$ [figura 2], ilustra o tamanho de uma bola de futebol comparada a uma molécula carbono $60\left(\mathrm{C}_{60}\right)$, também conhecida como buckyball. Para comparação, o mundo é aproximadamente cem milhões de vezes maior que uma bola de futebol, que por sua vez é cem milhões de vezes maior do que um buckyball. A secção de $10^{-7} \mathrm{~m}(100 \mathrm{~nm})$ a $10^{-9} \mathrm{~m}(1 \mathrm{~nm})$ é expandida abaixo. A escala de referência para nanociência e nanotecnologias é de $100 \mathrm{~nm}$ até a escala atómica - aproximadamente $0.2 \mathrm{~nm}$. (The Royal Society 2003). 


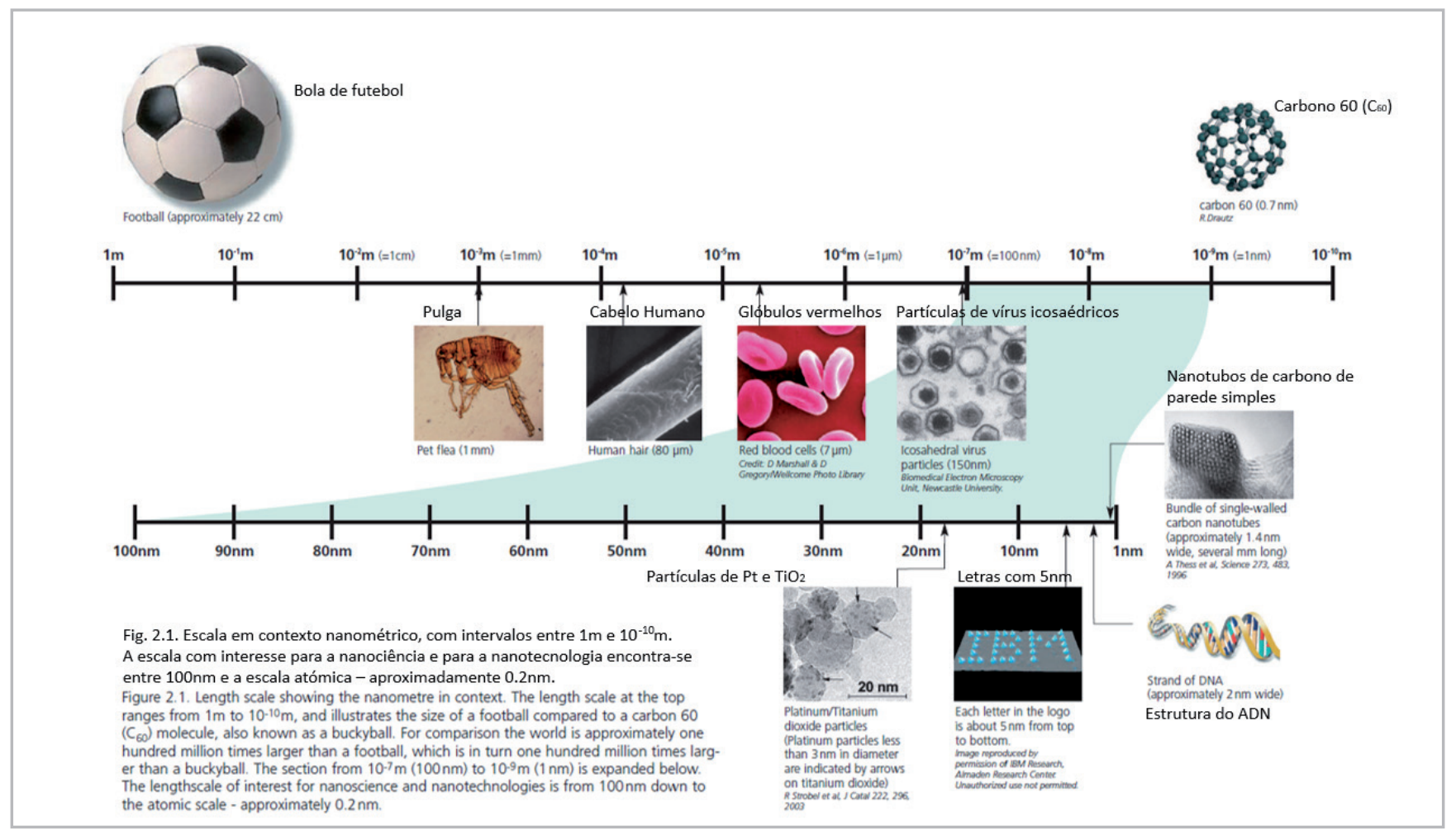

Figura 2.- Escala ilustrada de unidades de comprimento. (Fonte: The Royal Society 2003).

Nano: prefixo de unidade de medida na ordem de um bilionésimo de metro $\left(1 / 1.000 .000 .000=10^{-9}\right)=1 \mathrm{~nm}$. $\left[1 \mathrm{~mm}=1.000 .000 \mathrm{~nm}\left(10^{-3}\right) ; 1 \mu \mathrm{m}=1.000 \mathrm{~nm}\left(10^{-6}\right)\right]$

A nanotecnologia dedica-se ao estudo e fabricação de estruturas moleculares entre $1 \mathrm{~nm}$ e $100 \mathrm{~nm}$, tendo como objetivo fundamental é controlo da matéria ao nível do átomo (Schropfer 2011: 19). No entanto para que um dispositivo seja considerado Nanotecnológico será necessário apresentar propriedades diferenciadas associadas à sua nova condição em nano escala. A compreensão e o controle da matéria à escala entre 1 e 100nm - ciência a Nano escala, onde se manipula a matéria com atividades que envolvem a interação dos átomos e moléculas, projetando e construído materiais e sistemas funcionais, definem o termo Nanotecnologia (Roz et al 2015a: 3-12).

Do resultado da pesquisa realizada no ano de 2004 pela The Royal Society e pela The Royal Academy of Engineering, apresenta-se de uma forma sucinta, entre várias definições na literatura, as diferenças substanciais entre Nanotecnologia e Nanociência:

Nanociência: estudo dos fenómenos e manipulação à escala do átomo, molécula, em que suas propriedades físico-químicas são resultantes da condição associada à nano escala, diferindo significativamente das que tem em maior escala.

Nanotecnologia: controlo da forma e do tamanho à Nano escala, projetando, caracterizando e produzindo para aplicação prática nanoestruturas, dispositivos e sistemas (Netoy Pacheco et al 2012: 17-19).

A aplicação de materiais que apresentam propriedades físico-químicas resultantes dos fenómenos associados à nano escala - dimensões entre $1 \mathrm{~nm}$ a $100 \mathrm{~nm}$, dando origem a novos e melhores materiais, dispositivos e sistemas decorrentes dessa nova condição, disponíveis no mercado para as mais diversas aplicações, será uma contribuição desejável para uso em intervenções de reabilitação e conservação de Património Arquitetónico, pelo seu desempenho melhorado, na combinação com os materiais tradicionais, numa prévia e adequada seleção que garanta a necessária compatibilidade química com o substrato preexistente.

O seu desempenho melhorado, na combinação com os materiais tradicionais, numa prévia e adequada seleção que garanta a necessária compatibilidade química com o substrato preexistente, será um substancial contributo para uso em intervenções de reabilitação e conservação de Património Arquitetónico.

Da desagregação das micropartículas em múltiplas nanopartículas [figura 3] resulta um aumento da área superficial, sendo proporcional o aumento de átomos e consequentemente a sua maior reatividade e atividade catalítica, podendo, no entanto, o desempenho do catalisador ser aumentado de acordo com o formato da estrutura obtida - os poliedros de 26 e 18 faces têm maior capacidade de absorção e atividade fotocatalítica. Os átomos que se apresentam à superfície são mais reativos 

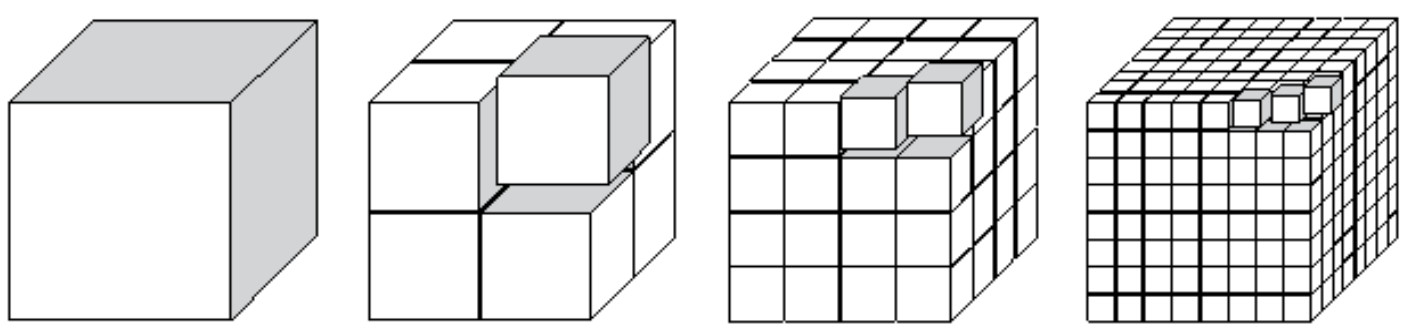

Figura 3.- Efeito da desagregação das partículas (Adaptado de Roz. et al, 2015a: 166). Aumento da área superficial, mantendo o volume original: A - 6 faces; B - 48 faces; C - 384 faces; D - 3072 faces.

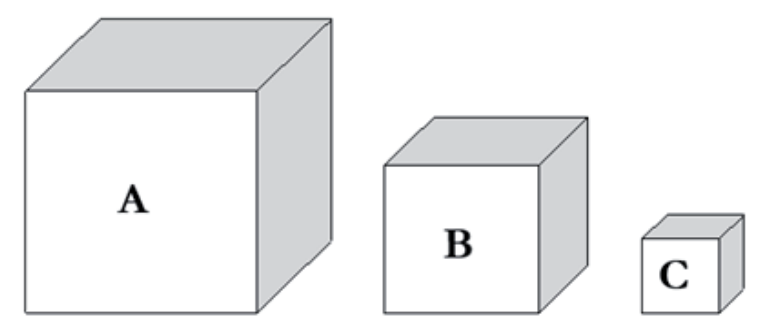

\begin{tabular}{|c|c|c|c|c|c|c|}
\hline Elementos/figuras & \multicolumn{2}{|c|}{ A } & \multicolumn{2}{c|}{ B } & \multicolumn{2}{c|}{ C } \\
\hline Dimensão da aresta & \multicolumn{2}{|c|}{3} & \multicolumn{2}{c|}{1} \\
\hline Área superficial $\left(\mathrm{x}^{2}\right)$ & $(3 \times 3) \times 6$ & 54 & $(2 \times 2) \times 6$ & 24 & $(1 \times 1) \times 6$ & 6 \\
\hline Volume $\left(\mathrm{x}^{3}\right)$ & $(3 \times 3 \times 3)$ & 27 & $(2 \times 2 \times 2)$ & 8 & $(1 \times 1 \times 1)$ & 1 \\
\hline S/V & 2 & 3 & 6 \\
\hline
\end{tabular}

Figura 4.- Relação superfície / volume (S/V).

que os restantes existentes no interior do volume das nanopartículas. (Gonçalves y Margarido, 2012:746-748; Roz et al 2015b: 77-80.)

As definições de um Nano material, quanto ao seu tamanho, baseiam-se em dois critérios:

- $50 \%$ das partículas integrantes do material terão de ter pelo menos uma das suas dimensões externas entre 1 a $100 \mathrm{~nm}$;

- O volume da área superficial específica - VASE, terá de ser maior que $60 \mathrm{~m} 2 / \mathrm{cm}^{3}$ (valor calculado a partir de uma esfera com 100nm de diâmetro)

OVASE de uma partícula determina assim a sua reatividade quando exposta ao meio. Com a diminuição das dimensões da partícula obtém-se uma maior proporção dos átomos na sua superfície, resultando uma maior área de contato externo, favorecendo as reações químicas catalíticas. Uma vez que este fenómeno acontece na superfície, uma determinada massa de material nano estruturado terá uma elevadíssima reatividade, aumentando o seu potencial catalítico, quando comparado com a mesma massa constituída por partículas maiores. Será, contudo, um dos grandes objetivos da investigação sobre a catálise o entendimento de como a diminuição das partículas não só aumenta a área de superfície com também influencia o seu desempenho catalítico intrínseco, numa procura de novas estruturas para produção de catalisadores de estruturas mais eficientes. (Berti, L. \& Porto, L. 2017: 17-33). À nano escala os componentes possuem uma relação superfície/volume muito maior [Figura 4], proporcionando as condições ideais para uma reatividade das partículas, com aumento da atividade catalítica dos semicondutores, distribuídos desta forma por uma superfície de contato substancialmente aumentada.

\section{Nanotubos De Carbono - NTC}

Com o desenvolvimento da indústria dos plásticos, depois milhares de anos de evolução tecnológica, a aplicação de polímeros reforçados de fibra - FRP fibre reinforced 
polymers, surge em meados dos anos 30 do século $X X$. Esta tecnologia de incorporação de fibras de reforço numa matriz polimérica vem dar resposta à necessidade de uso de materiais compósitos na construção. $O$ interesse da indústria da construção civil por esta nova tecnologia acontece nas décadas de $50 / 60$ do século $X X$, com a construção de edifícios protótipos, de conceção arquitetónica futurista, modular, tendo a aplicação dos compósitos se restringido essencialmente no revestimento das fachadas dos edifícios (Gonçalves y Margarido 2012: 576 - 577).

Na Rússia no decorrer do ano de 1952, são observados pela primeira vez os nanotubos de Carbono - NTC. Os NTC são, no entanto, redescobertos no Japão nos anos de 1990. Com uma resistência à tração 100 vezes superior à do aço, só o seu elevado custo inibe a sua vulgarização em utilizações correntes (Torga y Jalali 2010: 405). Os nanotubos de uma única camada detêm simultaneamente propriedades elásticas e grande resistência mecânica, chegando a atingir uma resistência à tração até 200GPa. As suas excelentes propriedades de condutividade elétrica e térmica aumentam o campo de utilização dos NTC na construção. (Loos 2014: 79-98).

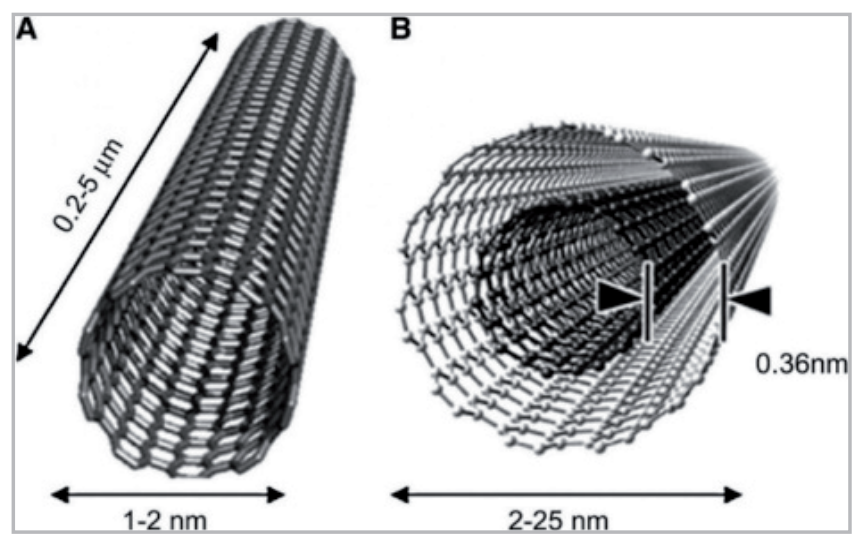

Figura 5.- Diagrama conceitual do nanotubo de carbono: Parede simples (SWCNT) (A) e parede múltipla (MWCNT) (B) (lijima ylchihashi 1993) (Fonte: Khalid et al. 2017).

Apresentando uma configuração particularmente estável de uma estrutura hexagonal tipo favos de mel, os NTC cinco vezes mais estáveis do que o aço e duas vezes mais duros que o diamante, formam tubos com apenas alguns nanómetros de espessura, vêm permitir a construção de sistemas de construção leve (Sascha 2014: 114-121).

Os nanotubos de carbono - NTC, apresentam-se como um nanomaterial com grande interesse para os arquitetos. Com a introdução de NTC nas intervenções de reabilitação de edifícios verifica-se um melhoramento da resistência à corrosão das ligas, promovendo a remoção de toxinas de perclorato da água contaminada. Os NTC - quando combinados com nano argilas, aumentam a resistência ao fogo dos plásticos, formando superfícies controláveis que podem alternar entre super-hidrofóbicas (que repelem a água) e hidrofílicas (que atraem a água).

A excecional força específica dos NTC, na constituição de nanocompósitos com uma relação força/peso substancialmente maior que qualquer outro tipo de material em uso, vem permitir múltiplas aplicações, nomeadamente em obras de estabilização estrutural dos edifícios.

Os NTC, material mais resistente e flexível criado pelo homem, quando adicionados no fabrico de betão conferem um melhoramento na resistência à tração, provocando um aumento na extensão granulométrica, proporcionando uma diminuição da porosidade. Estruturas mais resistentes e de maior durabilidade representam um menor impacto ambiental, reduzindo a necessidade de obras de manutenção, tornam-se mais sustentáveis (Sales 2013: 89-90; Berti y Porto 2017: 10-11).

Contudo, devido ao seu elevado preço, embora tenha vindo a cair ao longo dos últimos anos, os arquitetos continuam relutantes à introdução de nanotubos e nanomateriais em geral (Schropfer 2011: 139-140).

\section{Fotocatálise}

A fotocatálise é um fenómeno natural por meio do qual um composto, quando excitado pela radiação UV - ultravioleta, acelera a velocidade de uma reação química sem se consumir, resultando na reação de oxidação-redução (redox).

A fotocatálise confere características autolimpantes e descontaminantes às superfícies quando expostas à radiação UV, num processo natural - Honda - Fujishima effect - desenvolvido no Japão em 1972 pelo investigador Akira Fujishima (1942/), sob supervisão de Kenichi Honda (1924/2011). Este processo natural envolve a ativação de um semicondutor, excitado por radiação UV. Os semicondutores possuem uma camada de valência incompleta e uma camada condutora separada por uma "bandgap" (Fujishima, 2008) - [Figura 6].

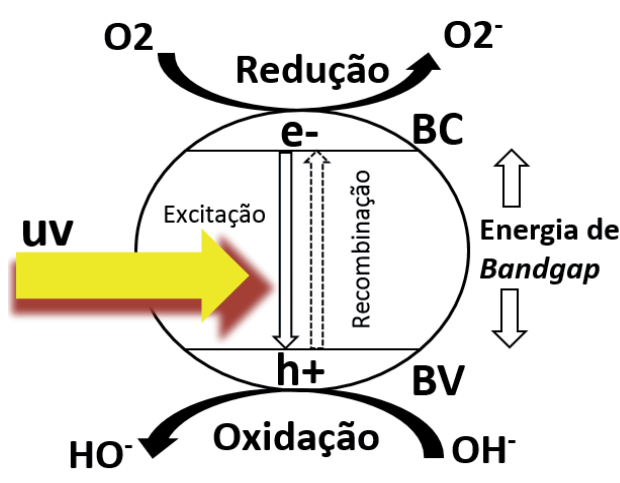

Figura 6.- Mecanismo Oxidação / Redução. Oxidação: agente redutor - perda de eletrões; aumento de NOx. Redução: agente oxidante - ganho de eletrões; diminuição de NOx 
A fotoexitação do $\mathrm{TiO} 2$, provocada pela radiação UV, de energia maior ou igual à energia da "bandgap" (banda de transferência), provoca a transferência de eletrões da banda de valência BV para a banda condutora BC. A energia gerada durante o processo químico é suficiente para degradar os resíduos acumulados, contribuindo para a descontaminação ambiental e autolimpeza do revestimento (Toma et al. 2016:171).

A determinação do ângulo de contacto da gota de um líquido com a superfície, associado aos parâmetros termodinâmicos relacionados com a tensão superficial, permite quantificar a hidrofobicidade de uma superfície, sendo que quanto maior for o valor do ângulo em análise, menos susceptível será a interação água/superfície. Quanto maior for o ângulo de contacto estático de um material menor será a sua "molhabilidade". O valor do ângulo de contacto de uma gota depositada sobre uma superfície determina a natureza hidrofílica ou hidrofóbica do material usado na sua composição, atribuindo-se as classificações de molhabilidade (Fujishima et al 2014):

- Superfície super-hidrofílica: com ângulo de contacto de baixo valor, próximo de $0^{\circ}$.

- Superfície hidrofílica: ângulos de contacto de baixo valor, até $30^{\circ}$.

- Superfície de características intermédias: ângulos de contacto entre $30^{\circ}$ até $90^{\circ}$.

- Superfície hidrofóbica: ângulo de contacto superior a $90^{\circ}$ e menores que $140^{\circ}$.

- Superfície super-hidrofóbica: com ângulo de contacto da água superior $140^{\circ}$.

A Flor de Lótus, cujas folhas repelem a água e mantêm a planta limpa, possui características naturais de sistemas Nanoestruturados comuns em vários elementos da natureza, que se podem encontrar também no reino animal. A rugosidade da superfície em associação com a fina espessura da sua camada, vem conferir às superficies uma dupla função: hidrofílica- nos seus picos e hidrofóbicas - nas reentrâncias.

Nas superfícies hidrofóbicas não se verifica a tendência natural de a água se espalhar, uma vez que o seu relevo não permite esse movimento, formando-se gotas esféricas que são expelidas da sua estrutura (Berti y Porto 2017: 3-11; Fujishima et al 2014). As Nano pilosidades existentes nas plantas resultam da evolução da natureza ao longo de milhares de anos, pelo que só através do seu estudo e compreensão das suas características será possível replicar estas estruturas, possibilitando a fabricação de materiais Nano estruturados que garantam uma desejável superhidrofobicidade das suas superfícies (Toma et al 2016: 1719).

Uma gota de água pode preencher a estrutura rugosa onde o líquido preenche completamente a estrutura de contacto [Figura 7a], ou manter-se acima dessa estrutura rugosa [Figura $7 \mathrm{~b}$ ], verificando-se que com o aumento da rugosidade superficial, uma superfície hidrofóbica se tornará mais hidrofóbica - super-hidrofóbica [Figura 7b]. Devido aos seus grandes ângulos de contato e baixos ângulos de deslizamento, a folha de lótus exibe diferentes comportamentos de molhamento sob diversas condições. Cheng et al. levantou uma interessante questão fundamental: "A folha de lótus é realmente superhidrofóbica?", concluindo que estas podem ser hidrofóbicas ou hidrofílicas, dependendo de como a água interage com a superfície da folha (Toma et al 2016: 15-19; Fujishima et al 2014).

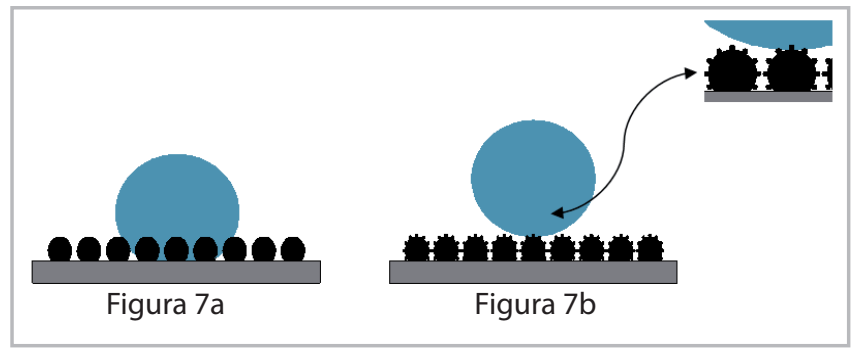

Figura 7.- Diferentes propriedades de molhabilidade da folha de lótus. (Adaptado de Fujishima, A. et al 2014).

Superfícies hidrofóbicas que simultaneamente adquirem propriedades hidrófilas - interação com a água, e oleofílicas - afinidade química com os óleos, são designadas por superfícies anfifilicas (Costa, J. et al, 2016: 2). A tensão superficial resultante da força de coesão existente entre moléculas controla a forma da gota do líquido, sendo que os surfactantes - compostos anfifílicos, substância que aumenta as propriedades lubrificadoras de um líquido baixando a tensão superficial da água, formam uma camada superficial de moléculas com influência direta na formação de interfaces líquidos/ar, líquido/líquido e líquido/sólido (Toma et al 2016: 15).

\section{Revestimentos fotocatalíticos aditivados com nano- partículas de $\mathrm{TiO}_{2}$}

A fotocatálise é um dos fenómenos mais conhecidos resultantes da aplicação de materiais Nanoestruturados no setor da Construção Civil, integrando semicondutores com capacidades fotocatalíticas na sua composição sob a forma de polímero ou incorporada na matriz do substrato. O semicondutor mais utilizado como catalisador em reações químicas é o Dióxido de Titânio $\left(\mathrm{TiO}_{2}\right)$, devido à sua baixa toxicidade, baixo custo, abundância e à sua estabilidade. É um óxido com 3 polimorfos principais: anatase; rutilo e brookite (Franco 2018: 129-131; Toma et al. 2016: 53).

Estudos revelam, no entanto, que a eficácia da reação fotocatalítica depende do tipo de $\mathrm{TiO}_{2}$ usado, concluindo que a mistura constituída por $30 \%$ de rutilo e $70 \%$ de anatase apresenta-se como a mais reativa (Torgal y Jalali 2010: 433). 
A capacidade bactericida na reação fotocatalítica é conseguida pelos radicais hidroxilos $\mathrm{OH}^{-}$, sendo que estes radicais hidroxilos possuem uma capacidade de eliminação da bactéria E. Coli entre 1.000 a 10.000 vezes superior aos desinfetantes químicos (Cho et al, in Torgal y Jaladi2010: 428-433). Os revestimentos fotocatalíticos, entre as suas múltiplas funcionalidades, conferem uma proteção permanente, prorrogando os períodos entre intervenções de manutenção, reduzindo os dispendiosos ciclos de limpeza, sem qualquer redução na sua eficácia, graças aos organossilanos funcionais, que tornam as suas superfícies antiaderentes, garantindo ainda a proteção contra a erosão das superfícies metálicas, (José y Prado2005: 281-288; Peters 2014: 127-128).

A dissociação e a desintegração de compostos orgânicos e/ou inorgânicos depositados na sua superfície são provocadas pelas capacidades fotocatalíticas das nanopartículas Dióxido de Titânio - $\mathrm{TiO}_{2}$, quando sujeito à radiação ultravioleta [Figura 8], aplicado sob a forma de polímero ou integrado na matriz do substrato. Este fenómeno natural reduz também o ângulo de contacto da água, tornando a superfície hidrofílica ou mesmo superhidrofílica, aumento substancialmente as propriedades de autolimpeza dos revestimentos.

Os revestimentos hidrofílicos em que a água se espraia como um filme fino sobre a superfície, em vez de ser repelida de imediato, proporcionam uma manutenção extremamente baixa das superfícies (Peters2014: 126-132). As superfícies autolimpantes veem assim permitir períodos mais alargados dos ciclos de limpeza, refletindo-se significativamente os custos de manutenção, com a redução da frequência das intervenções.

As propriedades super-hidrofílicas induzidas pelo nano $\mathrm{TiO}_{2}$ - sob a forma de polímeros ou por impregnação na matriz nas superfícies dos revestimentos, quando expostas à radiação UV, faz com que a água - da chuva ou de lavagem, adquira a forma de um filme contínuo, inibindo a formação de gotas, facilitando assim a lavagem da toda a área abrangida.

A - Autolimpeza do revestimento: a sujidade que se fixa na superfície ao longo da noite - ou na ausência de luz, é fragmentada sob o efeito da fotoativação do $\mathrm{TiO}_{2}$ e arrastada

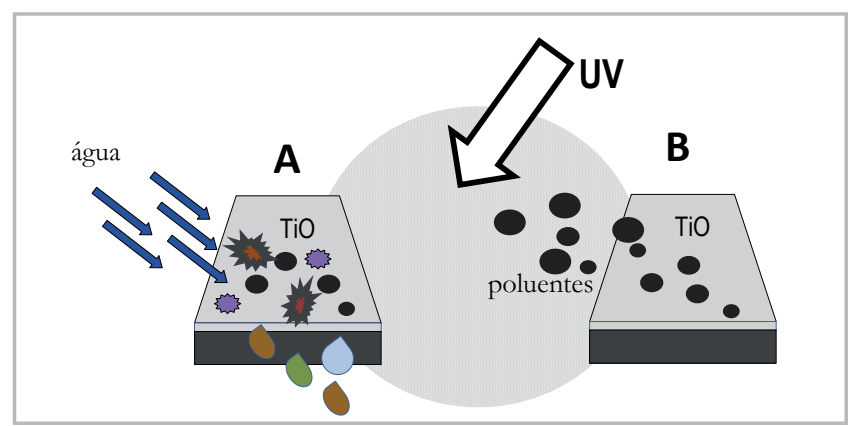

Figura 8.- Ação autolimpante e descontaminante. (Adaptado de www.picada-project.com [consulta: 14/07/2018]. pela ação da chuva ou aspersão: B - Descontaminação: os poluentes atmosféricos (NOx) são depositados na superfície e transformados em nitratos, eliminados pela matriz $\mathrm{TiO}_{2}$ do revestimento por ação de arrastamento provocada pela água (da chuva ou de lavagem)

A capacidade de descontaminação de uma área de fachadas com $1.000 \mathrm{~m}^{2}$ revestidas com materiais fotocatalíticos proporcionará uma ação de purificação do ar de forma tão eficaz quanto 70 árvores decíduas de tamanho médio, de acordo com estudos científicos realizados [Figura 9] (Sascha 2014: 122-185; Peters 2014: 126-132).

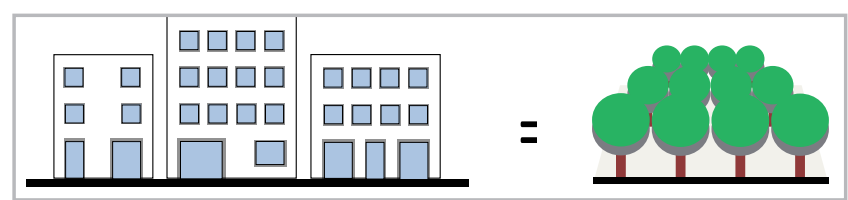

Figura 9.- Comparação do comportamento dos revestimentos Fotocatalíticos $\mathrm{TiO}_{2}$ em fachadas (Adaptado de Agrob Buchtal, 2018).

A fotocatálise pode-se assim comparar a outro fenómeno natural que acontece nas plantas - Fotossíntese, conforme ilustrado na Figura 10 (Fujishima, A., Hashimoto, K., \& Watanabe, T. (1999). $\mathrm{TiO}_{2}$ photocatalysis: Fundamentals and applications. Tokyo: Bkc), em que a clorofila - fotocatalisador muito poderoso existente nas plantas, atua como um catalisador para produzir oxigénio a partir de dióxido de carbono $\left(\mathrm{CO}_{2}\right)$ e água $\left(\mathrm{H}_{2} \mathrm{O}\right)$. O fotocatalisador no processo de fotocatálise corresponde à clorofila no processo de fotossíntese (Ohama y Van 2011:7-26).

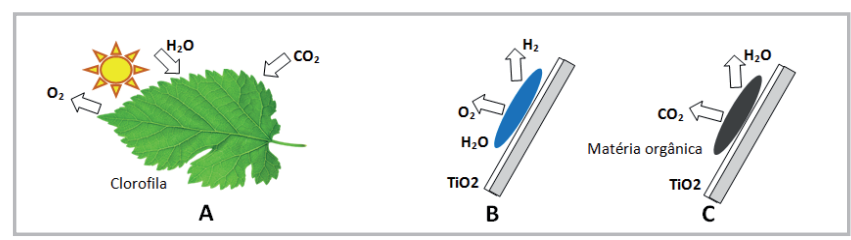

Figura 9.- Comparação entre a Fotossíntese das plantas e a atividade Fotocatalítica $\mathrm{TiO}_{2}$. A: Produção de $\mathrm{O}_{2}$ a partir do $\mathrm{CO}_{2}$ e cloroplasto - fotossíntese em plantas; $\mathrm{B}$ : Produção de $\mathrm{O}_{2}$ e $\mathrm{H}_{2}$ a partir da hidrólise da água - fotocatalisador $\mathrm{TiO}_{2}$; C: Produção de $\mathrm{CO}_{2}$ e $\mathrm{H}_{2} \mathrm{O}$ a partir da fotocatálise de matéria orgânica - fotocatalisador $\mathrm{TiO}_{2}$ (Fonte: Ohamay Gemert2011).

Materiais nanoestruturados com propriedades fotocatalíticas conferidas pela impregnação de nanopartículas de $\mathrm{TiO}_{2}$ na matriz das argamassas ou na composição de betão, quando usados nos revestimentos de paredes e/ou de pavimentos, fomentam a decomposição de fungos e bactérias que se depositam na sua superfície.

Asua capacidade de destruiçãoéde 1.000 a 10.000 vezes superior quando comparada aos efeitos da aplicação de desinfetantes químicos (CHO et al., in Torgal y Jaladi 2010: 428-433).

Em fachadas e em pavimentos urbanos a ação do $\mathrm{TiO}_{2}$ provoca a decomposição fotocatalítica de poluentes, 
convertendo dióxido de azoto $\left(\mathrm{NO}_{2}\right)$ em nitritos $\left(\mathrm{NO}_{2}^{-}\right)$e nitratos $\left(\mathrm{NO}_{3}{ }^{-}\right)$reduzindo os níveis de poluição da envolvente urbana em que se inserem. Superfícies antibacterianas com capacidades de inibir o crescimento microbial, contribuem de uma forma ativa para um ambiente mais saudável.

No âmbito do projeto europeu PICADA - Photocatalytic Innovative Coverings Applications for Depollution Assessmente, com o objetivo focado no estudo dos mecanismos reacionais fotocatalíticos, foram avaliados os benefícios da presença de $\mathrm{TiO}_{2}$ em materiais de construção e revestimentos, analisando as suas capacidades de autolimpeza e descontaminação ambiental, visando o desenvolvimento e otimização de formulação de materiais contendo $\mathrm{TiO}_{2}$, estabelecendo um modelo comportamental real em ambiente urbano, contribuindo ainda para a divulgação deste tipo de tecnologia.

O fabricante italiano Italcementi - no âmbito do projeto PICADA, tem vindo a desenvolver e a comercializar vários materiais de construção com propriedades fotocatalíticas, destacando-se as argamassas cimentícias, constituídas por cimento branco tipo Portland, incorporando nanopartículas de titânio (dimensões $21 \mathrm{~nm}$ ) com 0,5; 1,3 e 6\% ponderal de $\mathrm{TiO}_{2}$, num rácio anatase/rútilo de $80 \%$ / 20\%. Os ensaios realizados aos materiais aplicados demonstraram a redução da concentração em óxidos de azoto - N2O, da ordem de $60 \%$ ponderal numa rua no centro de Milão, repavimentada para a realização de testes com estes novos materiais.

Segundo estudos realizados pela Italcementi estima-se uma redução de $50 \%$ em $\mathrm{N}_{2} \mathrm{O}$ em ambiente urbano, se nessa mesma cidade $15 \%$ dos revestimentos dos edifícios fossem constituídos com superfícies com propriedades fotocatalíticas. A igreja Dives in Misericordia-Roma, projetada pelo arquiteto Richard Meier e concluída no ano de 2003, foi construída com betão branco incorporando $\mathrm{TiO}_{2}$ na sua matriz, produzido pela Italcementi (Gonçalves y Margarido (Eds.) 2012:761).Revestimentos antigraffiti para proteção de fachadas vêm reduzir recursos públicos necessários para a sua remoção. Materiais de ligação como adesivos e selantes para a indústria da construção civil, hidrofílicos e fáceis de limpar, quando aplicados em fachadas, garantem ainda proteção contra a corrosão metálica das superfícies.

Os revestimentos autolimpantes permitem alargar - período dos ciclos de limpeza, diminuindo significativamente os custos de manutenção. Materiais com auto cura e de longa duração, antibacterianos, com enzimas funcionais, purificadores de superfícies, revestimento aquecidos, vidros de metal, acústicos, fluidos expandidos e materiais de gradiente funcional, fibras de polímetros e têxteis óticos, materiais de direcionamento da luz, revestimentos antirreflexo, LED e OLED, materiais luminescentes, luz interativa, células eletroquímicas emissoras de luz - LEC, painéis fotovoltaicos orgânicosOPV e aerogel, acrescentam a longa lista de nanomateriais já disponíveis para aplicação na arquitetura e construção (Sascha 2014:. 122 - 185).

\section{Considerações finais}

A integração de nanopartículas de dióxido de titânio $\mathrm{TiO}_{2}$, na constituição de revestimentos, sob a forma de polímeros, tintas ou integrados na própria matriz do substrato, vem conferir propriedades fotocatalíticas às superfícies - resultante da aceleração de uma reação química quando expostas à radiação ultravioleta UV proveniente da luz natural em ambientes exteriores ou da luz artificial quando localizadas em espaços interiores, conferindo capacidades descontaminantes do ar, capazes de reduzir e decompor contaminantes como os óxidos de azoto (NO e $\mathrm{NO}_{2}$ designados por NOx), transformando-os em resíduos sólidos - nitritos e nitratos $\left(\mathrm{NO}_{2}\right.$ e $\left.\mathrm{NO}_{3}\right)$, facilmente removidos pela ação da água da chuva ou por aspersão. Sobre o efeito deste processo químico natural conhecido por fotocatálise, além do poder de descontaminação do ar, contribuindo para mitigação dos efeitos da poluição ambiental, as superfícies adquirem ainda propriedades de, entre outras, autolimpeza, bactericidas e de purificação do ar.

Apesar das capacidades de autolimpeza e poder de descontaminação do ar que os materiais nanoestruturados com propriedades fotocatalíticas serem conhecidas desde os anos 60 do século XX, podemos observar que a sua aplicação na construção civil em Portugal é residual. Torna-se assim imperioso enfatizar os benefícios que o uso de Nanomateriais com estas capacidades nos revestimentos de superfícies dos edifícios assim como nos pavimentos do espaço urbano, garantindo as superfícies limpas por períodos de tempo mais alargados, diminuindo recursos energéticos necessários nos trabalhos de manutenção, num inequívoco contributo para a melhoria da qualidade de vida nas cidades, aumentando a sustentabilidade da intervenção.

As notáveis propriedades química/físicas dos materiais nanoestruturados permitem várias aplicações no edificado emgeral enasobras dereabilitaçãoem particular.Aintrodução de nanotubos de carbono - NTC, o material mais resistente e flexível criado pelo homem, na composição de argamassas e de betões, proporciona, além do aumento das capacidades de resistência mecânica, uma diminuição da porosidade, permitindo múltiplas aplicações, nomeadamente em obras de estabilização estrutural dos edifícios.

O estudo de uma solução prática de intervenção devidamente adequada à preexistência, numa associação de materiais nanoestruturados já disponíveis no mercado com as técnicas de construção ancestrais, num contributo para a implementação do uso de Nanomateriais com novas características e novas propriedades, nas obras de reabilitação do Património Arquitetónico, que se querem pouco intrusivas e reversíveis, deverá garantir a autenticidade, na salvaguarda do legado que nos foi confiado.

A aplicação e o manuseamento de nanomateriais deverá ser precedida de uma avaliação cuidada das necessárias medidas de segurança a tomar, identificando a substância/ mistura e o fabricante, para uma correta caraterização da 
exposição, perigo e risco, controlando a exposição/proteção individual, uma vez que estamos presença de materiais muito recentes, não existindo grande conhecimento sobre os seus efeitos na saúde e no ambiente.

Deverão ser enfatizadas junto da Administração Pública as características e propriedades dos Nanomateriais quando introduzidas nos revestimentos exteriores do património arquitetónico, nomeadamente as de autolimpeza, descontaminantes, bactericidas e purificadoras do ar, propriedades que lhe são conferidas pelo fenómeno natural da Fotocatálise, recorrendo única e exclusivamente à energia proveniente da radiação UV emitida pelo sol - gratuita e inesgotável, e a importância que representam no âmbito da sustentabilidade nos seus três pilares: social, económico e ambiental, especialmente para as gerações vindouras.

\section{Referências}

BERTI, L. \& PORTO, L. (2016). Nanossegurança- Guia de boas práticas em nanotecnologia para fabricação e laboratórios. S. Paulo: Cengage Learning.

CARNEIRO, J. et al (2013). Utilização de nanopartículas de TIO2 para o desenvolvimento de pavimentos rodoviários com capacidade fotocatalítica. http://repositorium.sdum.uminho. pt/bitstream/1822/26160/1/Após\%20revisão JCar EF artigo 7CRP-1.pdf [consulta: 20/05/2019].

CHEN, D. et al (2007). Photocatalytic coating on road - pavements/ structures for NOx abatement. http://citeseerx.ist.psu.edu/viewdoc/ download?doi=10.1.1.604.5945\&rep=repy 1 \&type=pdf.[consulta: $15 / 11 / 2018]$.

COSTA, J. et al (2016). Materiais nanoestruturados para aplicação em edifícios históricos. https://www.researchgate. net/publication/309718395 Materiais nanoestruturados para aplicacao em edificios historicos/download. [consulta: 20/05/2019].

CRISTINA, I. et al. (2014). Responsabilidade civil e nanotecnologias. S. Paulo: Editora Atlas S.A.

FRANCO, C. (2018). “Nano materiais na reabilitação de património arquitetónico", em Tullio, F. \& Tullio, L. (Eds). (2018). Gestão de Projetos Sustentáveis, v. 1. Ponta Grossa: Atena Editora. https:// www.atenaeditora.com.br/wp-content/uploads/2018/10/E-bookGestão-de-Projetos-Sustentáveis.pdf [consulta: 18/11/2018].

FUJISHIMA, A. et al (2014). Superhydrophobic Surfaces Developed by Mimicking Hierarchical Surface Morphology of Lotus Leaf In Molecules, 19(4), 4256-4283. https://doi.org/10.3390/molecules 19044256. [consulta: 15/11/2018].

FUJISHIMA A. et al (2008). " $\mathrm{TiO}_{2}$ photocatalysis and related surface phenomena", em Surface Science Reports, 63 (15), 515582 https://www.sciencedirect.com/science/article/abs/pii/ S0167572908000757?via\%3Dihub.[consulta: 14/07/2018].
GOMES, M. (2014), Materiais de Construção Sustentáveis, in Obras Públicas Sustentáveis, 2, 523-531. http://repositorium.sdum. uminho.pt/handle/1822/31159. [consulta: 30/08/2015].

GONÇALVES, M. \& MARGARIDO, F. (2012). Ciência e Engenharia de Materiais de Construção. Lisboa: IST Press.

HEBEL, D. \& HEISEL, F. (2017). Cultivated building materials. Industrialized natural resources for architecture and construction. Basel: Birkhauser.

JOSÉ, N. \& PRADO, L. (2005). "Materiais Híbridos OrgânicoInorgânicos: Preparação e Algumas Aplicações", em Química Nova, 28 ( 2), 281-288. http://www.scielo.br/pdf/qn/v28n2/23651.pdf. [consulta: 18/11/2018].

KHALID M., RATNAM C.T., WALVEKAR R., KETABCHI M.R., HOQUE M.E. (2017). "Reinforced Natural Rubber Nanocomposites: Next Generation Advanced Material". Em JAWAID M., SALIT M., ALOTHMAN O. (eds) Green Biocomposites. Green Energy and Technology. Springer, Cham. DOI https://doi.org/10.1007/978-3319-49382-4 14. [consulta: 18/11/2018 ]

LIMA, E. (2014). Nanotecnologia: biotecnologia e novas ciências. Rio de Janeiro: Editora Interciência Ltda.

LOOS, M. (2014). Nanociência e nanotecnologia: compósitos termofixos reforçados com nanotubos de carbono. Rio de Janeiro: Editora Interciência Ltda.

LUCAS, S. et al (2014). Novos materiais de construção com tecnologias avançadas. Materiais de Construção Sustentáveis, 1, 71-77. http:// repositorium.sdum.uminho.pt/handle/1822/31367. [consulta: 18/11/2018].

MASS, W. et al. (2015). Barba-Live in the Fully Adaptable Environment. Amesterdam: The Why Factory.

NETO, O. y PACHECO, M. et al. (2012). Nanotecnologia computacional inteligente: concebendo a engenharia em nanotecnologia. Rio de Janeiro: Editora Interciência Ltda.

NETO, E. et al (2014). Efeitos da proteção antigraffiti na durabilidade do betão. Materiais de Construção Sustentáveis, 2, 449-459. http:// repositorium.sdum.uminho.pt/handle/1822/31159. [consulta: 30/08/2015].

OHAMA, Y. y GEMERT, D. (Eds). (2011). Application of Titanium Dioxide Photocatalysis to Construction Materials. Yokoama: Springer.

PAPPALARDO, J. et al (2014). Estudo sobre vigas de betão armado reforçadas com tecidos de fibra, Materiais de Construção Sustentáveis, 2, 709-719. http://repositorium.sdum.uminho.pt/ handle/1822/31159. [consulta: 30/08/2015].

PARAMÉS, J. y, BRITO, J. (2010). Materiais de construção nanotecnológicos de auto-limpeza, disponível em Teoria e Prática na Engenharia Civil, 15, 55-62. http://www.editoradunas.com.br/ revistatpec/Art6 N15.pdf. [consulta: 30-08-2015]. 
PETERS, S. (2014). Material revolution II - New sustainable and multipurpose materials for design and architecture. Basel: Birkhauser.

RÓZ, A. et al. (2015a). Técnicas de nanocaracteriação: princípios e aplicações. Rio de Janeiro: Elsevier Editora Ltda v1.

RÓZ, A. et al. (2015b). Nanoestruturas: princípios e aplicações. Rio de Janeiro: Elsevier Editora Ltda v2.

SANTOS, A. et al (2018). Design para a Sustentabilidade: Dimensão Ambiental. Curitiba: Editora Insight.

SASCHA, P. (2014). Material Revolution II - New sustainable and multi-purpose materials design and architecture. Basel: Birkhãuser,

SCHROPFER, T. (2011). Material Design - Informing Architecture by Materiality. Basel: Birkhãuser.

THE BRITISH MUSEUM (2019). The Lycurgus Cup. https://www. britishmuseum.org/research/collection online/collection object details/collection image gallery.aspx?partid=1\&assetid= 1066991001\&objectid=61219. [Consulta: 11-11-2018].

THE ROYAL SOCIETY (2003). Nanotechnology and Nanoscience. http://www.nanotec.org.uk/finalReport.htm. [consulta: 04-122018].

TORGAL, F. (2010). Considerações sobre a sustentabilidade dos materiais de construção. http://repositorium.sdum. uminho.pt/bitstream/1822/13957/1/CM Materiais 2010. pdf, [consulta:30/08/2015].TORGAL, F \& JALALI, S. (2010). A sustentabilidade dos Materiais de Construção. Vila Verde: Universidade do Minho.

TOMA, H. (2016). Nanotecnologia Molecular-Materiaisedispositivos. S. Paulo: Blucher.

TOMA, H. et al. (2016). Nanotecnologia experimental. S. Paulo: Blucher.

\section{Autor/es}

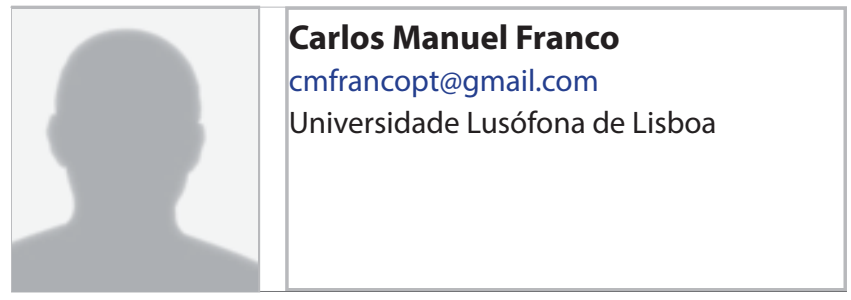

Carlos Manuel Franco, arquiteto mestre, doutorando em arquitetura na Universidade Lusófona de Lisboa, Investigador do LEAU - Laboratório Experimental de Arquitetura e Urbanismo desta Universidade, e no âmbito da sua Tese cujo tema é Nanomateriais na Reabilitação do Património Arquitetónico, vem desenvolvendo ao longo dos últimos anos, um trabalho que tem como um dos objetivos a procura de novos materiais de tecnologia de vanguarda, que possam vir a ser aplicados nas intervenções de reabilitação de Património
Arquitetónico, numa perspetiva de maior sustentabilidade, mais propriamente os materiais nanoestruturados - tecnologia já considerada como uma nova revolução industrial, com repercussões na sociedade a curto/médio prazo. Neste contexto tem desenvolvido artigos vários sobre a temática, como seja para a participação no Encontro de Sustentabilidade em Projeto-ENSUS2017, elaboração integral de um capítulo publicado no livro digital Gestão de Projetos Sustentáveis, participação no II Colóquio "Investigações em Conservação do Património", que decorreu em Setembro 2018 na Faculdade de Belas-Artes da Universidade de Lisboa, Expositor de trabalho oral no Congresso Mineiro de Direito do Património Cultural, evento realizado nos dias 24, 25 e 26 de outubro de 2018, na cidade de Ouro Preto, MG, Brasil. Presentemente faz parte do Grupo de Trabalho Para Adaptação às Alterações Climáticas, da CM Cascais, onde integrado no Departamento de Planeamento Estratégico, compartilha soluções e novos conceitos para o território, para a cidade e para os edifícios, visando a melhoria da qualidade de vida e fruição do espaço publico, sobretudo para as gerações vindouras.

Artículo enviado el 10/12/2018 Artículo aceptado el 26/06/2019 